\title{
Sedative and Anxiolytic-Like Actions of Ethanol Extract of Leaves of Glinus oppositifolius (Linn.) Aug. DC.
}

\author{
Md. Moniruzzaman, Partha Sharoti Bhattacharjee, Moushumi Rahman Pretty, \\ and Md. Sarwar Hossain
}

Department of Pharmacy, Stamford University Bangladesh, 51 Siddeswari Road, Dhaka 1217, Bangladesh

Correspondence should be addressed to Md. Moniruzzaman; moniruzzaman.babu@yahoo.com

Received 8 March 2016; Revised 17 May 2016; Accepted 26 May 2016

Academic Editor: Ki-Wan Oh

Copyright (C) $2016 \mathrm{Md}$. Moniruzzaman et al. This is an open access article distributed under the Creative Commons Attribution License, which permits unrestricted use, distribution, and reproduction in any medium, provided the original work is properly cited.

Glinus oppositifolius is a small herb, widely used in the traditional medicine of Bangladesh in treatment of a variety of diseases and disorders such as insomnia, pain, inflammation, jaundice, and fever. The present study evaluated the sedative and anxiolytic potentials of the ethanol extract of leaves of G. oppositifolius (EEGO) in different behavioral models in mice. The sedative activity of EEGO was investigated using hole cross, open field, rotarod, and thiopental sodium- (TS-) induced sleeping time determination tests, where the elevated plus maze (EPM) and light-dark box (LDB) exploration tests were employed to justify the anxiolytic potentials in mice at the doses of 50,100 , and $200 \mathrm{mg} / \mathrm{kg}$. The results demonstrated that EEGO significantly inhibited the exploratory behavior of the animals both in hole cross and in open field tests in a dose-dependent manner. It also decreased motor coordination and modified TS-mediated hypnosis in mice. In addition, EEGO showed anxiolytic potential by increasing the number and time of entries in the open arm of EPM, which is further strengthened by increase in total time spent in the light part of LDB. Therefore, this study suggests the sedative and anxiolytic properties of the leaves of G. oppositifolius and supports the traditional use of this plant in treatment of different psychiatric disorders including insomnia.

\section{Introduction}

Anxiety and insomnia are the most prevalent physiological and psychological states characterized by cognitive, emotional, and behavioral components affecting one-eighth of the world population [1]. Nowadays, several sedative drugs (e.g., diazepam, which is chosen as reference standard in this study) come with sanative potential to manage sleeping disorders, which also could reduce anxiety $[2,3]$. However, in addition to their beneficial properties, these currently available sedative and anxiolytic therapies possess serious adverse and side effects. Therefore, newer, more efficacious and bettertolerated treatments including alternative/complementary medicines would be a welcome addition in the therapeutic repertoire of insomnia and anxiety management.

Glinus oppositifolius (family: Molluginaceae) is a very common herb in Bangladesh, locally known as "gima shak." This plant is extensively used by the local people as a vegetable and the traditional healers as an essential ingredient in treatment of a wide range of diseases and disorders including pain, inflammation, jaundice, diarrhea, boils, and malaria [4]. This herb is also useful for its diuretic, CNS depressant, anthelmintic, and antiviral properties in the folk medicine of this country [5]. In recent years, several studies have been conducted to identify the phytochemical constituents of G. oppositifolius and a number of phytochemicals including L-(-)-( $N$-trans-cinnamoyl)-arginine, kaempferol 3-O-galactopyranoside, isorhamnetin 3-O- $\beta$-D-xylopyranosyl-( $1 \rightarrow 2)$ - $\beta$-D-galactopyranoside, and L-phenylalanine have been isolated from different parts of this plant [6]. Further studies have revealed that G. oppositifolius also contains spergulagenin derivatives [4], oppositifolone [7], and a bioactive pectic polysaccharide having immunomodulatory properties [8]. According to the aforementioned medicinal properties and the presence of different bioactive phytochemicals, researchers tried to validate its traditional uses against different diseases and disorders. Their findings revealed that G. oppositifolius is effective as an antioxidant, hypoglycemic, 
anti-inflammatory [4], antidiarrheal, and anthelmintic [5] agent. However, till now there is no scientific report revealing its actions on the central nervous system. This influenced us to design and conduct the present study to evaluate the impact of ethanol extract of leaves of $G$. oppositifolius in different behavioral models in mice.

\section{Materials and Methods}

2.1. Plant Collection and Extraction. Glinus oppositifolius leaves were collected from Khilgaon, Dhaka, during the spring of 2013. The collected samples were then identified by Mr. Sardar Nasir Uddin, Senior Scientific Officer, Bangladesh National Herbarium (Mirpur, Dhaka, Bangladesh). A voucher specimen has been deposited with a number DACB: 38355 for further references. The powdered dried leaves $(250 \mathrm{~g})$ were macerated with $450 \mathrm{~mL}$ of ethanol (100\%; Merck, Bremen, Germany) with occasional stirring at room temperature for three days. Then the filtrate was collected and completely dried using a rotary evaporator. Finally $11.83 \mathrm{~g}$ extract (yield $4.73 \%$ ) was obtained which was further used in the entire set of studies.

2.2. Animals. Adult Swiss albino mice (20-25 g) were purchased from the Animal Resources Branch of the International Center for Diarrheal Disease Research, Bangladesh (icddr,b), and housed in standard laboratory conditions (relative humidity 55-60\%; room temperature $25 \pm 2^{\circ} \mathrm{C}$; $12 \mathrm{~h}$ light/dark cycle) with standard diet (icddr,b formulated) and water ad libitum. Animals were acclimatized with the experimental environment for a period of 14 days prior to the experiments and then treated according to the "Ethical Principles and Guidelines for Scientific Experiments on Animals" (1995) drafted by the Swiss Academy of Medical Sciences and the Swiss Academy of Sciences. All experimental protocols employed in this study were approved by the Institutional Ethics Committee of Stamford University Bangladesh (SUB/IAEC/14.08).

2.3. Drugs and Treatments. Mice were divided into five groups containing 5-7 animals each for control, standard, and test samples, for every experiment. Standard drug diazepam (1 mg/kg; i.p.) (Square Pharmaceuticals Ltd., Dhaka, Bangladesh), EEGO (50, 100, and $200 \mathrm{mg} / \mathrm{kg}$; p.o.), or vehicle (DMSO; $0.1 \mathrm{~mL} / \mathrm{mouse}$; p.o.; Merck), was administered to the animals, immediately after taking the pretreatment reading in hole cross and open field tests. For the rest of the models, diazepam was administered at $15 \mathrm{~min}$ and EEGO or vehicle at $30 \mathrm{~min}$ before the experiments. In sleeping time determination test, the sleep inducer thiopental sodium $(20 \mathrm{mg} / \mathrm{kg})$ (Square) was administered $15 \mathrm{~min}$ posttreatment with diazepam and $30 \mathrm{~min}$ of vehicle or EEGO.

2.4. Phytochemical Screening. The crude extract of G. oppositifolius leaves was qualitatively analyzed to detect the presence of alkaloids, glycosides, carbohydrates, saponins, flavonoids, tannins, glucosides, and reducing sugars following standard procedures [9].
2.5. Acute Toxicity Test. Mice were divided into desired groups each containing 5-7 animals. EEGO was administered to the animals orally at the doses of 500, 1000, and $2000 \mathrm{mg} / \mathrm{kg}$. The mice were then allowed to take food and water ad libitum and observed for the next $72 \mathrm{~h}$ to check any allergic symptoms and mortality induced by EEGO [10].

\subsection{Sedative Activity Analysis}

2.6.1. Hole Cross Test. A cage having a size of $30 \times 20 \times 14 \mathrm{~cm}$ with a fixed partition in the middle having a hole of $3 \mathrm{~cm}$ diameter was used in this experiment [11]. Mice were treated with either vehicle or drug or EEGO and allowed to cross the hole from one chamber to another. The animals were then observed for $3 \mathrm{~min}$ and the number of passages was recorded before and at 30, 60, 90, and $120 \mathrm{~min}$ following the treatments.

2.6.2. Open Field Test. This test is a widely used model for the evaluation of emotional behavior of the animals, especially the rodents. The method was carried out as described by Gupta et al. (1971) [12]. The open field apparatus consisted of a wooden field of half square meter with a series of squares alternatively painted in black and white. It had a wall of $50 \mathrm{~cm}$ height and was placed in a dimly lit room. The animals were placed in the middle of the open field to explore freely and the number of squares visited by them was counted for 3 minutes as pretreatment reading. Immediately after taking the reading the animals were treated with vehicle, extract, or diazepam and observed repeatedly at 30,60, 90, and $120 \mathrm{~min}$ after the treatments.

2.6.3. Test for Motor Coordination (Rotarod Test). The rotarod test was performed according to the procedure described by Dunham and Miya (1957) [13]. This test is effective for the investigation of motor impairment due to pharmacological agents like muscle relaxants or CNS depressants. The apparatus consisted of a horizontal nonslippery plastic rod, rotating at $20 \mathrm{rpm}$. The animals which can remain in the rotating rod for more than $180 \mathrm{sec}$ were selected for this study. After desired treatments, each mouse was placed on the rod and the falling time of each mouse within $180 \mathrm{sec}$ was recorded as an indication of muscle relaxation.

2.6.4. Thiopental Sodium-Induced Sleeping Time Determination. Thiopental sodium-induced sleeping time test was performed according to the previously described method [14]. Following desired sample or drug administration, the animals were observed for the latent period (time to lose their righting reflex, immediately after thiopental sodium injection) and the duration of sleep (time between the loss and recovery of reflex) induced by thiopental sodium.

\subsection{Investigations for the Anxiolytic Potential}

2.7.1. Elevated Plus Maze Test. The elevated plus maze (EPM) test is a widely used model to investigate anxiolytic effects. The apparatus consists of two open arms $\left(15 \times 5 \mathrm{~cm}^{2}\right)$ and two closed arms $\left(15 \times 5 \times 5 \mathrm{~cm}^{3}\right)$, extending from a central 
platform $\left(5 \times 5 \mathrm{~cm}^{2}\right)$ and raised $50 \mathrm{~cm}$ above floor level. Animals were randomly divided into each group and treated with EEGO, vehicle, or diazepam. After the desired time, each animal was placed at the center of the plus maze facing its head to the closed arms and allowed free exploration for $3 \mathrm{~min}$. Then the number of entries and total time spent in open arms were recorded within the indicated time $[15,16]$.

2.7.2. Light-Dark Box (LDB) Exploration Test. The apparatus is an open-topped rectangular box $\left(46 \times 27 \times 30 \mathrm{~cm}^{3}\right)$, divided into a small $\left(18 \times 27 \mathrm{~cm}^{2}\right)$ and a large $\left(27 \times 27 \mathrm{~cm}^{2}\right)$ compartment with a fixed partition containing a small hole of $3 \mathrm{~cm}$ diameter in the middle. The small compartment was closed with a lid, painted black, and illuminated with a dim light. On the other hand, a $60 \mathrm{~W}$ electric light was used in the large compartment (painted white) to make it brightly illuminated. After $30 \mathrm{~min}$ of successful oral gavage of vehicle, EEGO, or diazepam, mice were placed in the middle of the open compartment of LDB. The animals were then observed for $3 \mathrm{~min}$ and the time spent in the lighted compartment and the total number of transitions in between the compartments were registered [17].

2.8. Statistical Analysis. The results are presented as Mean \pm SEM. The statistical analysis was performed using two-way analysis of variance (ANOVA) followed by Bonferroni's post hoc test for hole cross and open field tests, where one-way ANOVA followed by Dunnett's post hoc test was employed for other experiments performed in this study. All statistical analyses were performed using SPSS software. Besides, the $\mathrm{ED}_{50}$ values were calculated using GraphPad Prism and the figures were drawn using SigmaPlot software.

\section{Results and Discussion}

The present study evaluated the effect of an ethanol extract of G. oppositifolius on CNS using several behavioral models in mice. Our results demonstrated that, following oral administration, EEGO was able to promote CNS depressant and anxiolytic effects. Moreover, EEGO at the doses of 500$2000 \mathrm{mg} / \mathrm{kg}$ did not produce any allergic manifestation or mortality of the animals during $72 \mathrm{~h}$ of observation period, which is in line with the wide dietary and therapeutic uses of this plant. This nontoxic profile of the extract also made us capable of choosing the experimental doses in this study.

The hole cross and open field tests are the most common experimental models used to investigate the exploratory behavior of the animals. It is well established that several drugs like benzodiazepines suppress curiosity of the animals about a new environment resulting in a decrease in their locomotor activity $[11,18]$. Likewise, our results demonstrated that EEGO significantly $(p<0.01)$ reduced locomotion of the animals both in hole cross and in open field tests. The suppressive effect was observed from $30 \mathrm{~min}$ and continued up to 120 min of EEGO administration (Figures 1 and 2) accounting 81 and $92 \%$ of locomotor inhibition at the highest time point of these tests, respectively. Besides, it is well established that the CNS depressant drugs like benzodiazepines cause muscle

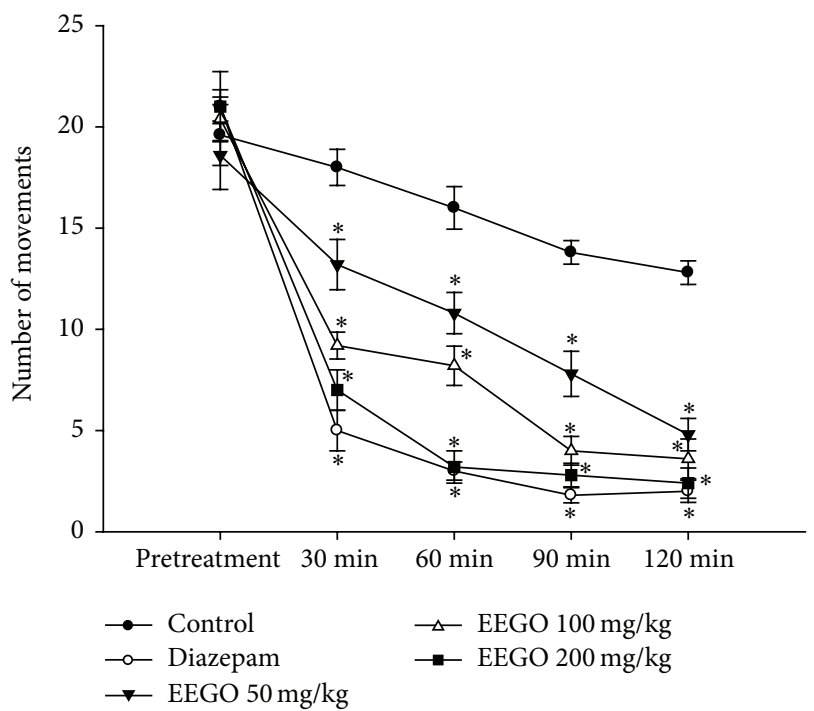

FIGURE 1: Effect of EEGO on hole cross test in mice. Before and after treatments with diazepam, vehicle, or EEGO the number of holes crossed in the hole cross box was recorded at different time points. Data were presented as Mean $\pm \operatorname{SEM}(n=5-7) .{ }^{*} p<0.01$ compared to control.

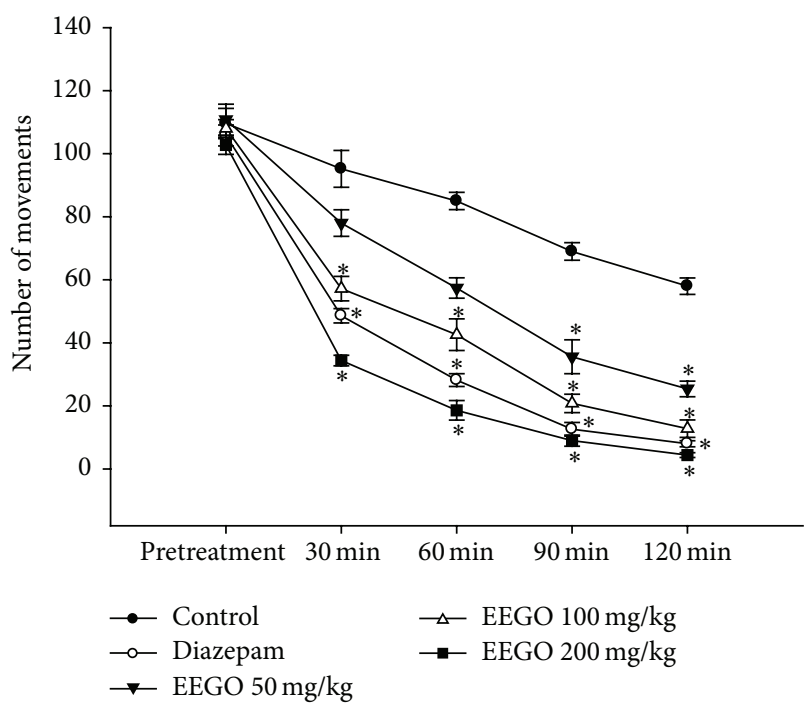

FIGURE 2: Effect of EEGO on open field test in mice. Before and after treatments with diazepam, vehicle, or EEGO the number of squares crossed in the open field box was recorded at different time points. Data were presented as Mean $\pm \operatorname{SEM}(n=5-7) .{ }^{*} p<0.01$ compared to control.

weakness [19], decreased ambulatory activity, and sedation which negatively affect the rotarod performance of the animals [20,21]. As depicted in Figure 3, EEGO decreased the falling latency of the animals from rotarod, significantly $(p<$ 0.01 ) with the doses of 100 and $200 \mathrm{mg} / \mathrm{kg}$. The highest motor coordination impairment and $\mathrm{ED}_{50}$ were calculated as $58 \%$ with $200 \mathrm{mg} / \mathrm{kg}$ and $89.66 \mathrm{mg} / \mathrm{kg}$, respectively. In parallel, diazepam at $1 \mathrm{mg} / \mathrm{kg}$ dose also produced similar pattern of effects observed with EEGO in all experiments. From these 


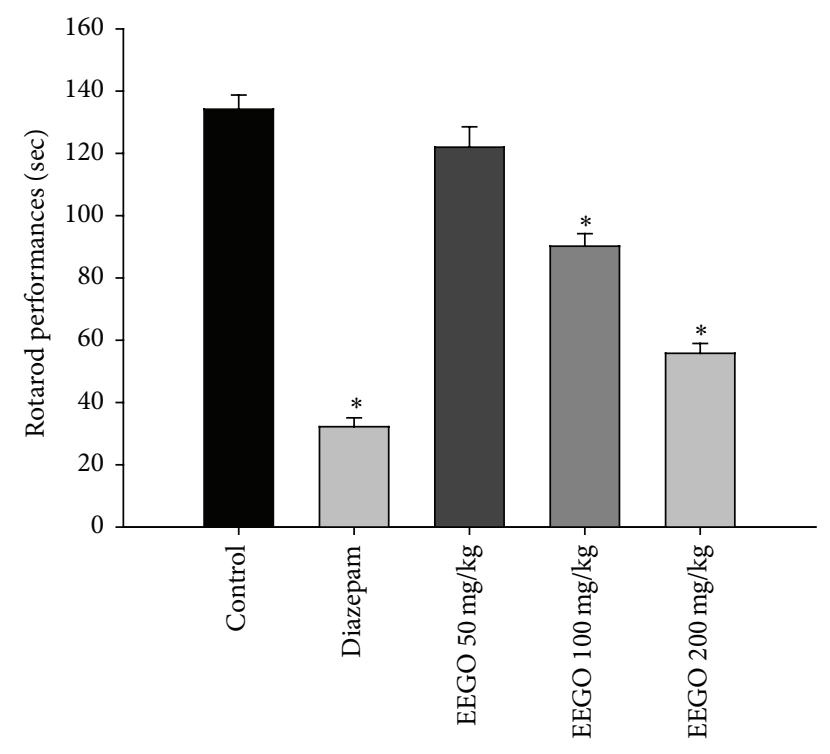

FIGURE 3: Effect of EEGO on motor coordination of mice. Thirty min after the treatment with EEGO or vehicle and 15 min after diazepam, rotarod performances by the animals were observed for $180 \mathrm{sec}$. Data were presented as Mean $\pm \operatorname{SEM}(n=5-7) .{ }^{*} p<0.01$ compared to control.

observations, it is conceivable that, like diazepam, EEGO may have the potential to act on CNS which was reflected by its locomotor inhibitory activity as well as impaired motor coordination effects in the animals.

Further evidence of the central sedative activity of EEGO is provided by TS-induced sleep enhancing ability of the extract. Substantial scientific reports suggested that the CNS depressant barbiturates like TS bind to the barbiturate binding site of the $\mathrm{GABA}_{\mathrm{A}}$ receptor, which potentiates GABAmediated hyperpolarization of the neurons [22]. In our study, the acute oral administration of EEGO significantly $(p<$ 0.01 ) modulated the sleeping behavior of the animals induced by TS. We found that EEGO decreased TS-induced onset of sleeping and increased the sleeping duration in a dosedependent manner (Figures $4(\mathrm{a})$ and $4(\mathrm{~b})$ ) with the $\mathrm{ED}_{50}$ value of $69.73 \mathrm{mg} / \mathrm{kg}$. Therefore, these results strengthened the sedative and muscle relaxation potentials of the extract observed in hole cross, open field, and rotarod tests.

The elevated plus maze is a widely used behavioral model in rodents and has been validated to investigate the anxiolytic potential of different pharmacological agents [23]. The open arm activities of the animals in EPM reflect a conflict between the animal's innate behavior to keep itself in a protected area (e.g., closed arms) and motivation to explore in a novel environment, where the anxiolytic agents induce the exploratory activities of the rodents in the open arm $[15,24]$. Our results demonstrated that EEGO caused a marked increase in the number of entries as well as the time the animals spent in the open arms of EPM (Figures $5(\mathrm{a})$ and $5(\mathrm{~b}))$. However, the significant $(p<0.01)$ effect was observed with 100 and $200 \mathrm{mg} / \mathrm{kg}$ doses of EEGO and the $\mathrm{ED}_{50}$ values were calculated as 88.65 and $92.87 \mathrm{mg} / \mathrm{kg}$ for the number of entries and time spent, respectively. In

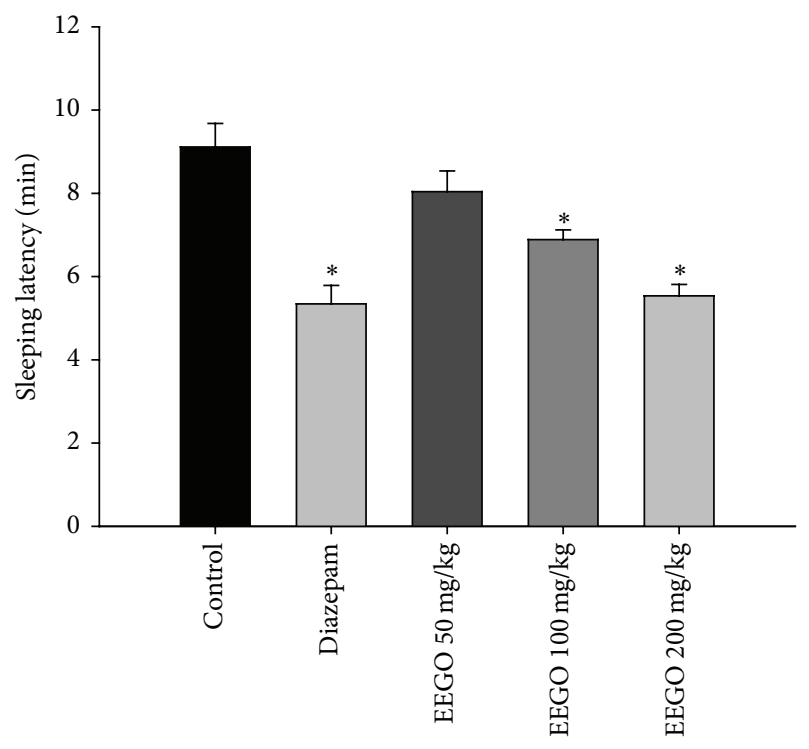

(a)

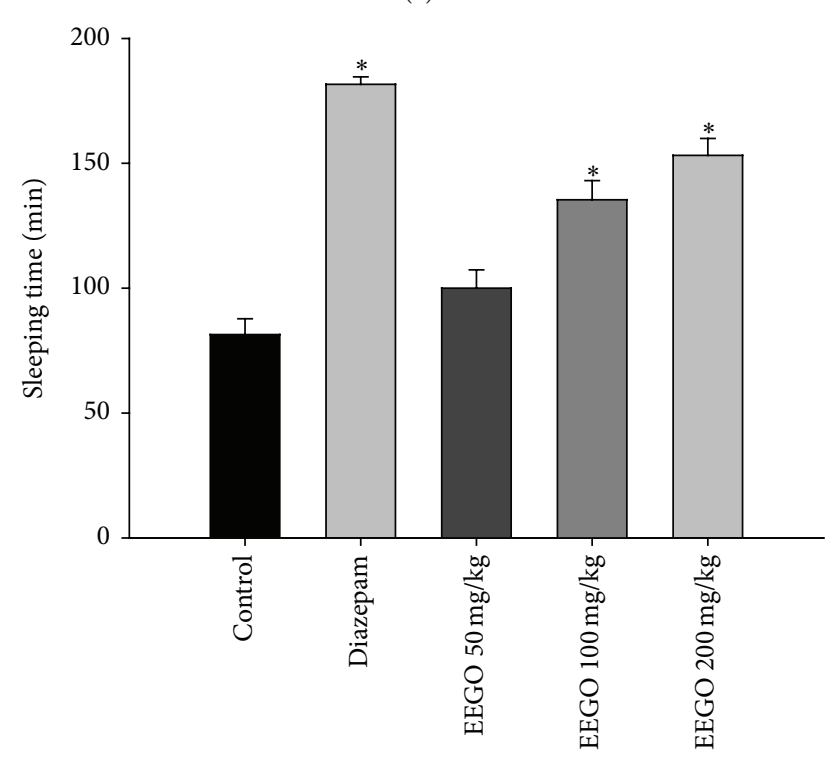

(b)

FIGURE 4: Effect of EEGO on TS-induced hypnosis in mice. Thirty min after the treatment with EEGO or vehicle and 15 min after diazepam, TS was administered intraperitoneally. Then the latency to sleep (a) and total sleeping duration (b) induced by TS were observed. Data were presented as Mean $\pm \operatorname{SEM}(n=5-7) .{ }^{*} p<0.01$ compared to control.

addition, the effect of EEGO was also evaluated using LDB, a popular screening tool in research of anxiolytic or anxiogenic agents [25]. The present study demonstrated that the oral administration of EEGO at 100 and $200 \mathrm{mg} / \mathrm{kg}$ doses could significantly $(p<0.01)$ increase the time the animals spent in the lighted area $\left(\mathrm{ED}_{50}: 82.46 \mathrm{mg} / \mathrm{kg}\right)$ without altering the total number of transitions in between the compartments. As expected, diazepam also exhibited similar patterns of effects of EEGO in these models (Figures 6(a) and 6(b)). Substantial scientific reports demonstrated that, with an 


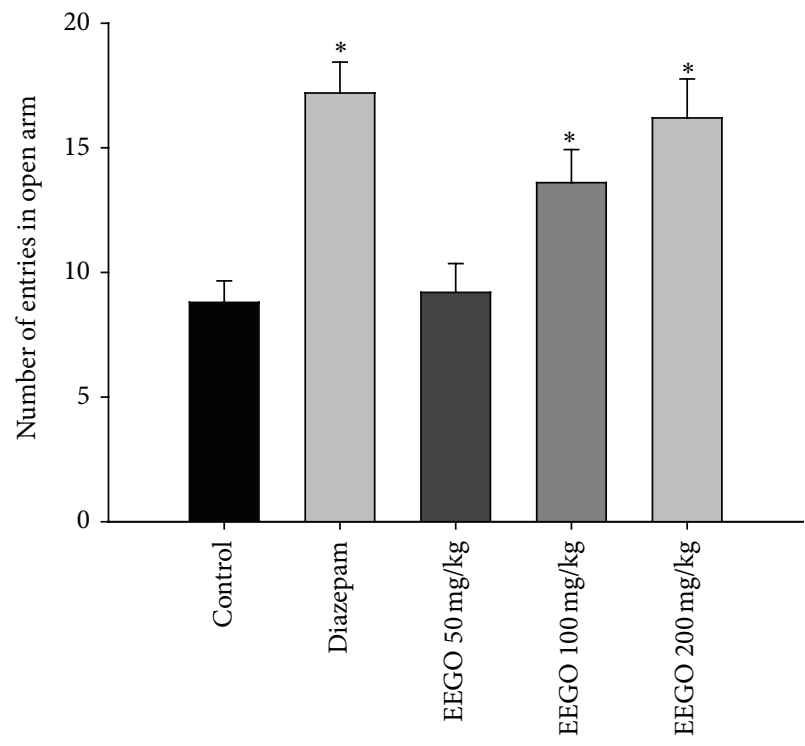

(a)

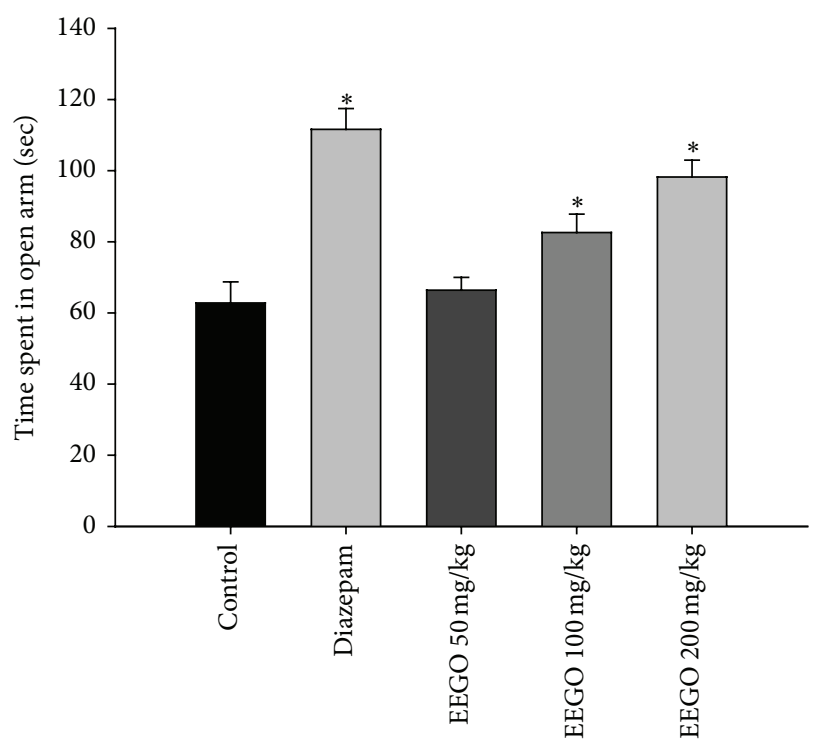

(b)

FIGURE 5: Effect of EEGO on elevated plus maze (EPM) test in mice. Thirty min after the treatment with EEGO or vehicle and 15 min after diazepam, animals were observed for their number of entries (a) and total time spent (b) in the open arms of EPM. Data were presented as Mean $\pm \operatorname{SEM}(n=5-7) .{ }^{*} p<0.01$ compared to control.

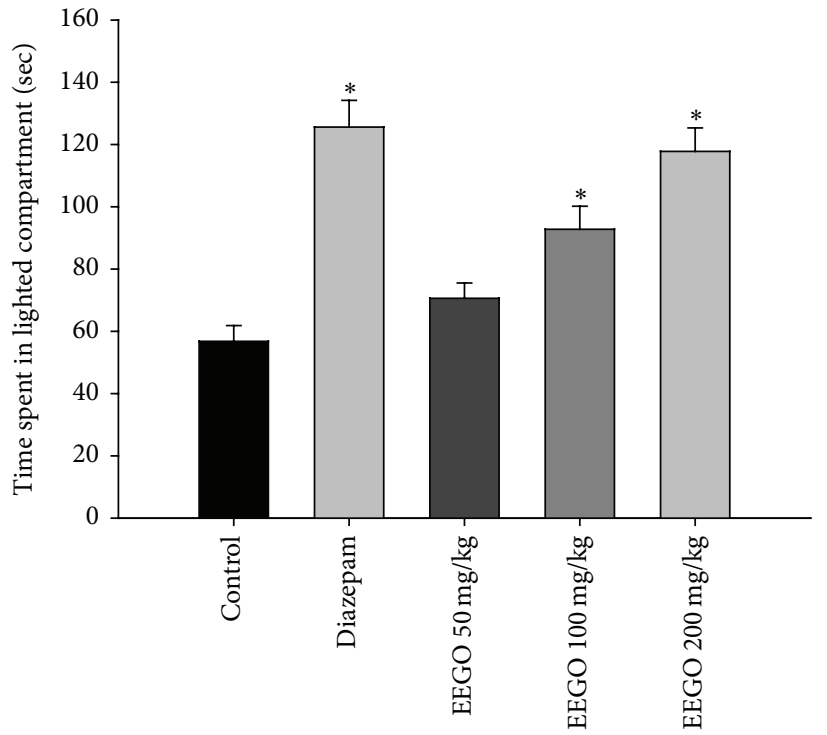

(a)

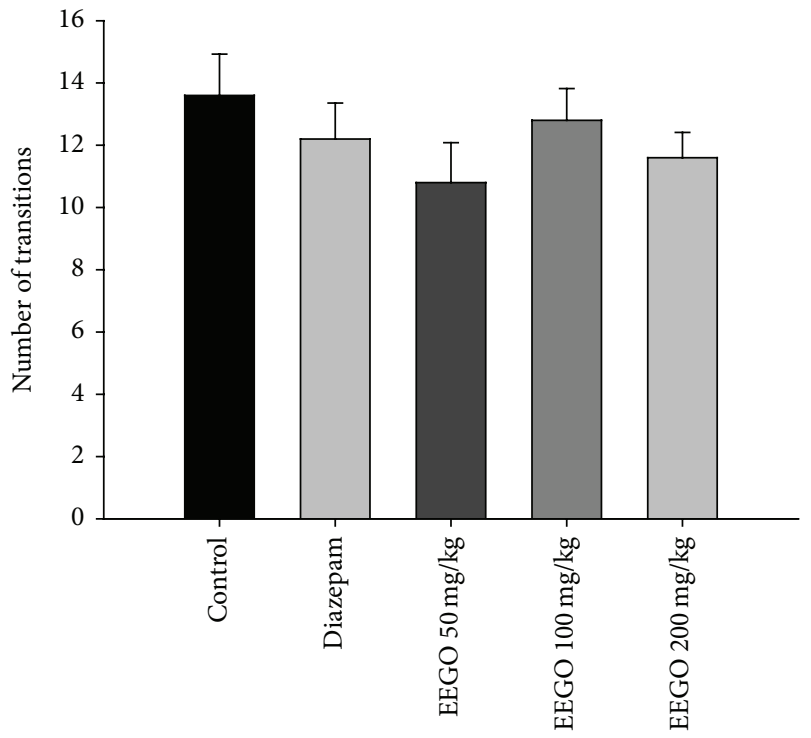

(b)

FIGURE 6: Effect of EEGO on light-dark box (LDB) exploration test in mice. Thirty min after the treatment with EEGO or vehicle and 15 min after diazepam, animals were observed in LDB and the time spent in the lighted part (a) and number of transitions between compartments (b) were recorded. Data were presented as Mean $\pm \operatorname{SEM}(n=5-7) .{ }^{*} p<0.01$ compared to control.

anxiolytic drug treatment, animals increased their transitions in between the compartments of LDB. In contrast, there were no changes observed by other researchers when they administered standard anxiolytics to their animals. These discrepancies might be due to the genetic or strain variation of the animals used in their studies. Therefore, it has been concluded that simply the time spent in the lighted area, but not the total number of transitions, is the most useful and consistent parameter to evaluate an anxiolytic action [25]. Therefore, our results and previously published reports suggest that EEGO may possess anxiolytic potentials along with its sedative properties (Figure 7). Although this research has reached its goals, the audience of this paper might have the query regarding the effects of higher doses of EEGO on the above models. Therefore, it is worthy to include few more doses (higher than $200 \mathrm{mg} / \mathrm{kg}$ ) in the future studies. 


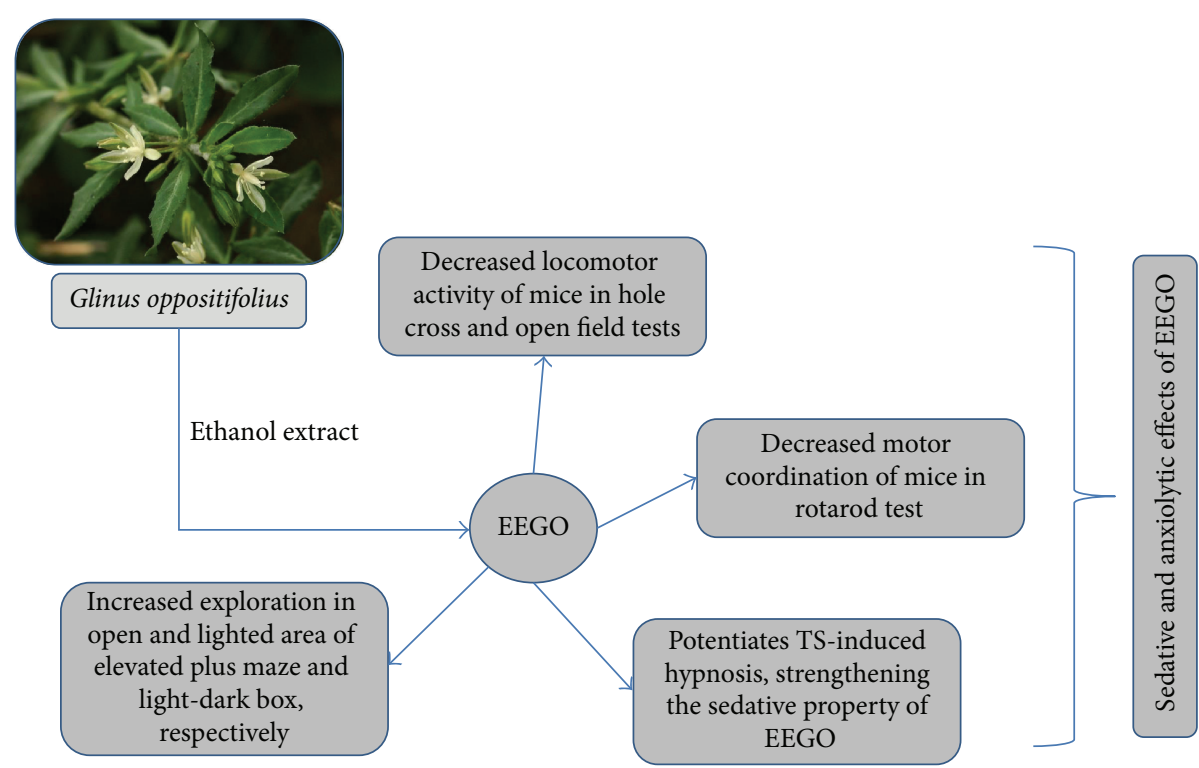

FIGURE 7: Sedative and anxiolytic activities of EEGO.

TABLE 1: Groups of phytochemicals identified in EEGO.

\begin{tabular}{|c|c|c|c|}
\hline Phytochemicals & Name of the tests & Expected changes & Results \\
\hline \multirow{5}{*}{ Alkaloids } & Mayer's test & Yellowish buff color precipitate & + \\
\hline & Hager's test & Yellow crystalline precipitate & + \\
\hline & Wagner's test & Brown or deep brown precipitate & + \\
\hline & Dragendorff's test & Orange or orange-brown precipitate & + \\
\hline & Tannic acid test & Buff color precipitate & - \\
\hline \multirow{2}{*}{ Tannins } & Ferric chloride test & Blue-green color & + \\
\hline & Alkaline reagent test & Yellow to red precipitate & + \\
\hline \multirow{2}{*}{ Glycosides } & General test & Yellow color & + \\
\hline & Test for glucoside & Production of brick-red precipitation & + \\
\hline \multirow{4}{*}{ Carbohydrates } & Molisch's test & $\begin{array}{l}\text { A red or reddish violet ring is formed at the junction of two } \\
\text { layers and on shaking a dark purple solution is formed }\end{array}$ & + \\
\hline & $\begin{array}{l}\text { Barfoed's test (general test for } \\
\text { monosaccharides) }\end{array}$ & Red precipitate & - \\
\hline & Fehling's test & A red or brick-red precipitate & + \\
\hline & Test for reducing sugar & A brick-red precipitate & + \\
\hline Flavonoids & Hydrochloric acid reduction test & Red color & + \\
\hline Saponins & Frothing test & Formation of stable foam & + \\
\hline
\end{tabular}

Our phytochemical screening of EEGO revealed the presence of alkaloids, carbohydrates, flavonoids, glycosides, saponins, and tannins (Table 1), where saponins are known to show amphetamine antagonism and sedative property and decrease spontaneous motor activity in the experimental animal models [26]. It has also been reported that the presence of alkaloids, glycosides, and flavonoids in plant extract possess sedative and anxiolytic effect through the interaction with $\mathrm{GABA}_{\mathrm{A}}$ receptors [27-29]. Considering our results and previously published reports, it is possible that the abovementioned chemical components in the extract might contribute at least in part to the observed pharmacological activities. We may, therefore, conceive that the ethanol extract of G. oppositifolius contains psychoactive principles that are sedative and anxiolytic in nature.

\section{Conclusion}

Our preliminary pharmacological studies suggest that the ethanol extract of Glinus oppositifolius leaves possesses sedative properties, reduces locomotor activity, and causes muscle relaxation in experimental animals, which authorize the possible anxiolytic-like actions of the extract. Therefore, these results provide the scientific validation for the use of this 
plant in traditional medicine in treatment of various ailments related to CNS disorders. However, further pharmacological studies are required to clearly understand the sedative and anxiolytic actions of EEGO, where our findings could stand as a basis for further progress. In addition, whether these activities were generated by the actions of agonists or partial agonists present in EEGO which could directly act on the receptor(s) responsible and/or interact with other molecular mechanism(s) involved in the observed sedative-anxiolytic effects also needs to be investigated. These bioactivity-guided phytopharmacological works will give us the opportunity to identify pharmaceutical lead(s) with better tolerability and lesser side effects in new drug development.

\section{Disclosure}

The present address of Md. Moniruzzaman is the Centre for Pain Research, Institute for Molecular Bioscience, The University of Queensland, Brisbane, QLD 4072, Australia.

\section{Competing Interests}

The authors wish to confirm that there are no known competing interests associated with this paper and there has been no significant financial support for this work that could have influenced its outcome.

\section{Acknowledgments}

The authors are thankful to Md. Ripon Mia and Protik Roy for their support in animal handling.

\section{References}

[1] D. H. Barlow, B. F. Chorpita, and J. Turovsky, "Fear, panic, anxiety, and disorders of emotion," Nebraska Symposium on Motivation, vol. 43, pp. 251-328, 1996.

[2] D. S. Charney, S. J. Mihic, and R. A. Harris, "Hypnotics and sedatives," in Goodman \& Gilman's the Pharmacological Basis of Therapeutics, L. L. Brunton, J. S. Lazo, and K. L. Parker, Eds., McGraw-Hill Medical, New York, NY, USA, 2006.

[3] A. J. Trevor and W. L. Way, "Sedative hypnotic drugs," in Basic and Clinical Pharmacology, B. G. Katzung, Ed., McGraw-Hill Medical, New York, NY, USA, 2007.

[4] N. Hoque, M. Z. Imam, S. Akter et al., "Antioxidant and antihyperglycemic activities of methanolic extract of Glinus oppositifolius leaves," Journal of Applied Pharmaceutical Science, vol. 1, no. 7, pp. 50-53, 2011.

[5] S. Pattanayak, S. S. Nayak, S. C. Dinda, and D. Panda, "Preliminary anti-diarrhoeal activity of aerial parts of Glinus oppositifolius (L.) in rodents," Recent Advances in Pharmaceutical Science Research, vol. 1, no. 2, pp. 50-57, 2012.

[6] P. Sahakitpichan, W. Disadee, S. Ruchirawat, and T. Kanchanapoom, "L-(-)-(N-trans-cinnamoyl)-arginine, an acylamino acid from Glinus oppositifolius (L.) Aug. DC.," Molecules, vol. 15, no. 9, pp. 6186-6192, 2010.

[7] C. Y. Ragasa, D. L. Espineli, E. H. Mandia, M.-J. Don, and C.C. Shen, "A new triterpene from Glinus oppositifolius," Chinese Journal of Natural Medicines, vol. 10, no. 4, pp. 284-286, 2012.
[8] K. T. Inngjerdingen, S. C. Debes, M. Inngjerdingen et al., "Bioactive pectic polysaccharides from Glinus oppositifolius (L.) Aug. DC., a Malian medicinal plant, isolation and partial characterization," Journal of Ethnopharmacology, vol. 101, no. 13, pp. 204-214, 2005.

[9] A. Ghani, Medicinal Plants of Bangladesh with Chemical Constituents and Uses, Asiatic Society of Bangladesh, Dhaka, Bangladesh, 2nd edition, 2003.

[10] C. I. B. Walker, G. Trevisan, M. F. Rossato et al., "Antinociceptive activity of Mirabilis jalapa in mice," Journal of Ethnopharmacology, vol. 120, no. 2, pp. 169-175, 2008.

[11] K. Takagi, M. Watanabe, and H. Saito, "Studies of the spontaneous movement of animals by the hole cross test; effect of 2-dimethyl-aminoethanol and its acyl esters on the central nervous system," Japanese Journal of Pharmacology, vol. 21, no. 6, pp. 797-810, 1971.

[12] B. D. Gupta, P. C. Dandiya, and M. L. Gupta, "A psychopharmacological analysis of behaviour in rats," Japanese Journal of Pharmacology, vol. 21, no. 3, pp. 293-298, 1971.

[13] N. W. Dunham and T. S. Miya, "A note on a simple apparatus for detecting neurological deficit in rats and mice," Journal of the American Pharmaceutical Association, vol. 46, no. 3, pp. 208209, 1957.

[14] R. A. Turner, "Anticonvulsant," in Screening Methods in Pharmacology, Academic Press, New York, NY, USA, 1st edition, 1965.

[15] S. Pellow, P. Chopin, S. E. File, and M. Briley, "Validation of open: closed arm entries in an elevated plus-maze as a measure of anxiety in the rat," Journal of Neuroscience Methods, vol. 14, no. 3, pp. 149-167, 1985.

[16] M. Goyal and D. Sasmal, "CNS depressant and anticonvulsant activities of the alcoholic extract of leaves of Ziziyphus nummularia," Journal of Ethnopharmacology, vol. 151, no. 1, pp. 536-542, 2014.

[17] M. Hascoët and M. Bourin, "A new approach to the light/dark test procedure in mice," Pharmacology Biochemistry and Behavior, vol. 60, no. 3, pp. 645-653, 1998.

[18] L. Prut and C. Belzung, "The open field as a paradigm to measure the effects of drugs on anxiety-like behaviors: a review," European Journal of Pharmacology, vol. 463, no. 1-3, pp. 3-33, 2003.

[19] C. López-Rubalcava, R. Hen, and S. L. Cruz, "Anxiolytic-like actions of toluene in the burying behavior and plus-maze tests: differences in sensitivity between $5-\mathrm{HT}_{1 \mathrm{~B}}$ knockout and wildtype mice," Behavioural Brain Research, vol. 115, no. 1, pp. 85-94, 2000.

[20] S. Farkas, P. Berzsenyi, E. Kárpáti, P. Kocsis, and I. Tarnawa, "Simple pharmacological test battery to assess efficacy and side effect profile of centrally acting muscle relaxant drugs," Journal of Pharmacological and Toxicological Methods, vol. 52, no. 2, pp. 264-273, 2005.

[21] R. Estrada-Reyes, M. Martínez-Vázquez, A. Gallegos-Solís, G. Heinze, and J. Moreno, "Depressant effects of Clinopodium mexicanum Benth. Govaerts (Lamiaceae) on the central nervous system," Journal of Ethnopharmacology, vol. 130, no. 1, pp. 1-8, 2010.

[22] S. Fernández, C. Wasowski, A. C. Paladini, and M. Marder, "Sedative and sleep-enhancing properties of linarin, a flavonoid-isolated from Valeriana officinalis," Pharmacology Biochemistry and Behavior, vol. 77, no. 2, pp. 399-404, 2004.

[23] A. A. Walf and C. A. Frye, "The use of the elevated plus maze as an assay of anxiety-related behavior in rodents," Nature Protocols, vol. 2, no. 2, pp. 322-328, 2007. 
[24] S. L. Handley and S. Mithani, "Effects of alpha-adrenoceptor agonists and antagonists in a maze-exploration model of "fear"motivated behaviour," Naunyn-Schmiedeberg's Archives of Pharmacology, vol. 327, no. 1, pp. 1-5, 1984.

[25] R. Young and D. N. Johnson, "A fully automated light/dark apparatus useful for comparing anxiolytic agents," Pharmacology, Biochemistry and Behavior, vol. 40, no. 4, pp. 739-743, 1991.

[26] H. Wagner, S. Ott, K. Jurcic, J. Morton, and A. Neszmelyi, "Chemistry, 13C-NMR study and pharmacology of two saponins from Colubrina asiatica," Planta Medica, vol. 48, no. 3, pp. 136-141, 1983.

[27] P. Kahnberg, E. Lager, C. Rosenberg et al., "Refinement and evaluation of a pharmacophore model for flavone derivatives binding to the benzodiazepine site of the $\mathrm{GABA}_{\mathrm{A}}$ receptor," Journal of Medicinal Chemistry, vol. 45, no. 19, pp. 4188-4201, 2002.

[28] R. Awad, F. Ahmed, N. Bourbonnais-Spear et al., "Ethnopharmacology of Q'eqchi' Maya antiepileptic and anxiolytic plants: effects on the GABAergic system," Journal of Ethnopharmacology, vol. 125, no. 2, pp. 257-264, 2009.

[29] R. Estrada-Reyes, C. López-Rubalcava, L. Rocha, G. Heinze, A. R. González Esquinca, and M. Martínez-Vázquez, "Anxiolyticlike and sedative actions of Rollinia mucosa: possible involvement of the GABA/benzodiazepine receptor complex," Pharmaceutical Biology, vol. 48, no. 1, pp. 70-75, 2010. 


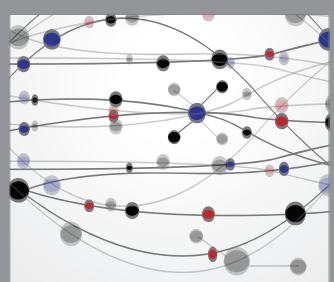

The Scientific World Journal
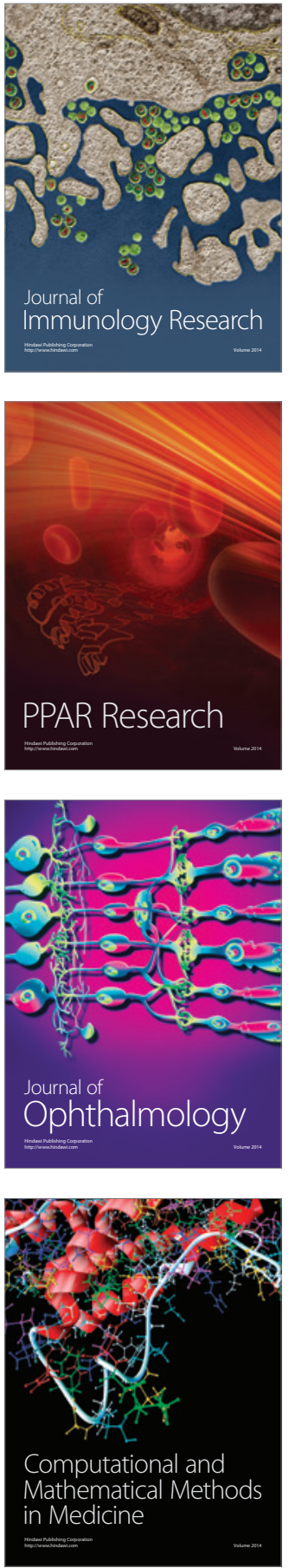

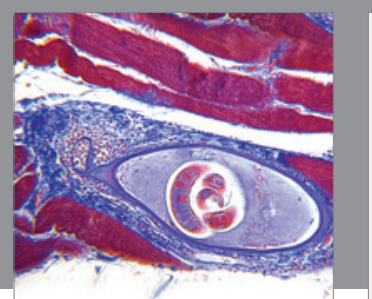

Gastroenterology Research and Practice

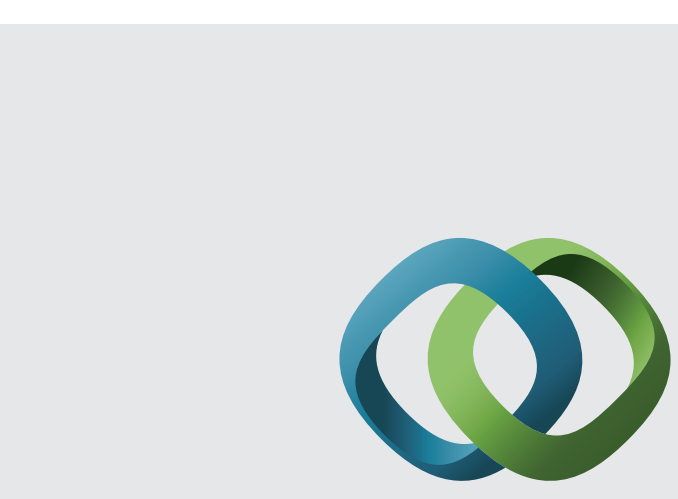

\section{Hindawi}

Submit your manuscripts at

http://www.hindawi.com
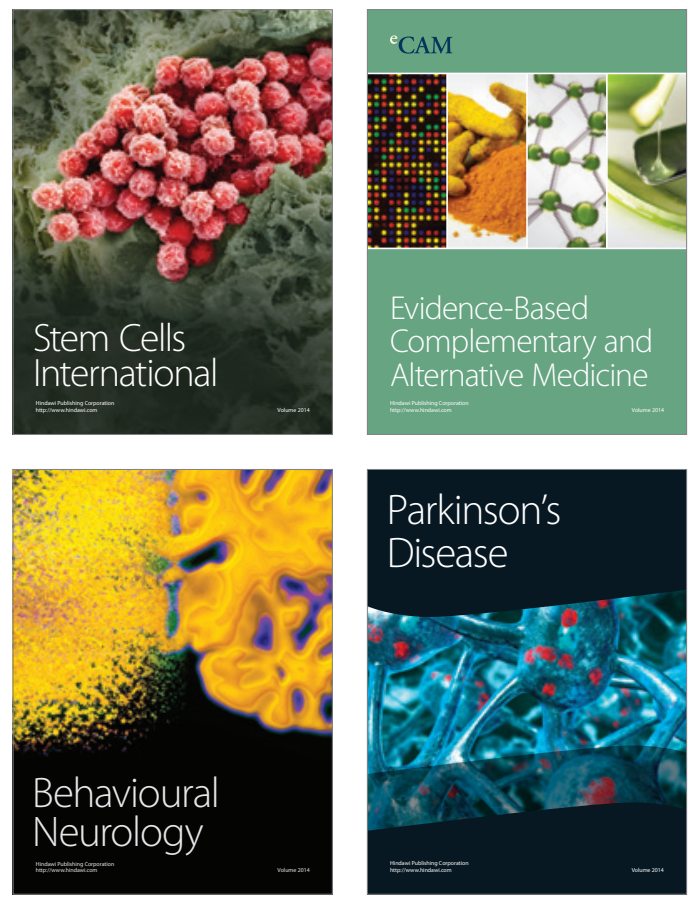
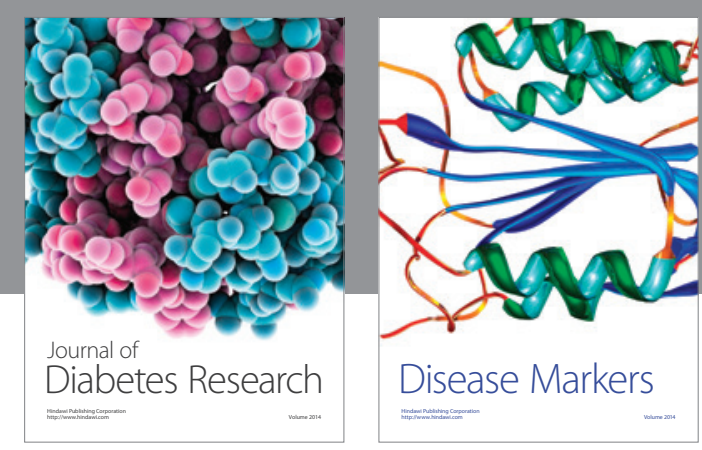

Disease Markers
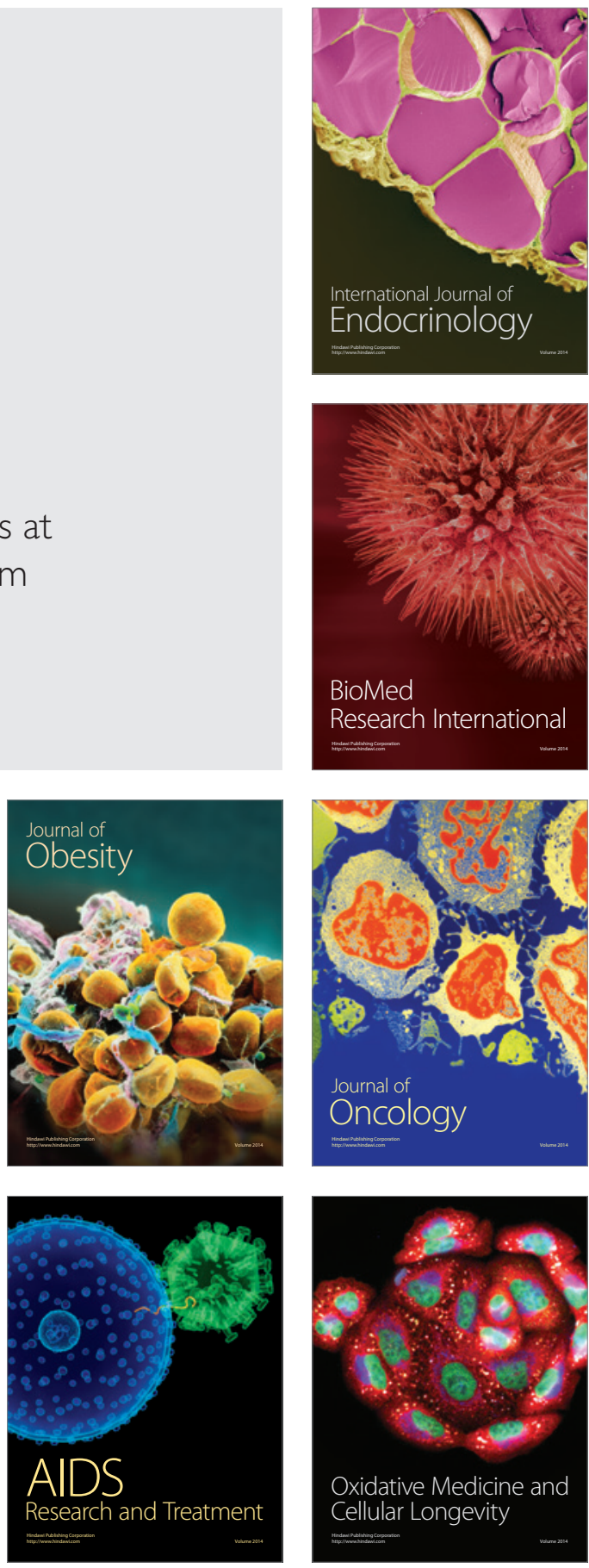